\title{
PEMODELAN REGRESI LOGISTIK PADA FAKTOR YANG MEMPENGARUHI PHBS PADA RUMAH TANGGA PENDERITA TBC DI PESISIR SURABAYA
}

\author{
Destri Susilaningrum ${ }^{1,}$ Harun Al Azies ${ }^{2}$, \\ ${ }^{1,2}$ Departemen Statistika Bisnis, Fakultas Vokasi Institut Teknologi Sepuluh Nopember \\ Kampus ITS, Keputih Sukolilo Surabaya, Indonesia 60111 \\ destr.s@gmail.com, harunalazies@gmail.com
}

\begin{abstract}
ABSTRAK
Provinsi Jawa Timur merupakan salah satu dari tiga provinsi di Indonesia dengan jumlah kasus TBC terbesar yakni mencapai 23.487 kasus dimana angka penderita TBC yang tertinggi di Jawa Timur adalah di Kota Surabaya, sedikitnya 4.739 warga bermukim di Surabaya yang terkena penyakit TBC. Penyakit ini banyak ditemukan di permukiman padat penduduk dengan sanitasi yang kurang baik, kurangnya ventilasi dan pencahayaan matahari dan kurangnya istirahat seperti diwilayah pesisir. Penyakit TBC yang diderita masyarakat tersebut mempengaruhi perilaku hidup masyarakat dalam menjaga kesehatan dan kebersihan. Padahal dengan berperilaku hidup bersih dan sehat tersebut dapat mengurangi resiko penularan TBC sehingga dapat menurunkan jumlah penderita TBC, oleh karena itu Dinas Kesehatan menyelenggarakan program PHBS bagi masyarakat yang menderita TBC Penelitian ini bertujuan untuk menentukan faktor-faktor yang mempengaruhi status PHBS rumah tangga penderita TBC di pesisir Surabaya Metode yang digunakan adalah regresi logistik biner. Hasil analisis menunjukkan bahwa kebiasaan membuka pintu dan jendela, kebiasaan merokok dan minum alkohol, kebiasaan olahraga, makanan bergizi, kebiasaaan cuci tangan dengan sabun dan air bersih, istirahat cukup, pemisahan peralatan mandi dan makan berpengaruh signifikan $(\alpha=5 \%)$ terhadap PHBS rumah tangga dengan penderita TBC di pesisir Surabaya.
\end{abstract}

Kata kunci: Regresi Logistik Biner, PHBS, Penderita, Rumah Tangga, TBC

\section{PENDAHULUAN}

Perilaku Hidup Bersih dan Sehat atau lebih dikenal dengan sebutan PHBS ada lah semua perilaku kesehatan yang dilaku kan atas kesadaran setiap anggota keluar ga sehingga anggota keluarga atau keluar ga dapat menolong dirinya sendiri dibi dang kesehatan dan dapat berperan aktif dalam kegiatan-kegiatan kesehatan dimasyarakat (Anonim_1, 2008). Dengan ber perilaku hidup bersih dan sehat, maka tingkat kesehatan masyarakat semakin tinggi. Terkait dengan permasalahan ting kat kesehatan atau penyebaran penyakit berbasis lingkungan salah satunya penya kit Tuberkulosis (TBC) sangat diperlukan kesadaran masyarakat maupun rumah tang ga dalam ber-PHBS. PHBS di rumah tang ga dengan penderita TBC dilakukan untuk mencapai Rumah Tangga berPHBS, yaitu

rumah tangga yang melakukan 10 (sepu- 
E-ISSN : 2549-7464, P-ISSN : 1411-3724

uh) kriteria PHBS di rumah tangga, antara lain menjemur peralatan tidur, membuka pintu dan jendela setiap pagi agar udara dan sinar matahari masuk, makan buah dan sayur setiap hari, tidak merokok di dalam rumah dan tidak memi num minuman keras, olahraga secara teratur, mencuci pakaian hingga bersih, mencuci tangan dengan air bersih dan sabun, menggu nakan jamban sehat, istira hat cukup, jangan tukar menukar peralatan mandi. PHBS merupakan peri laku yang berkaitan erat dengan munculnya penyakit infeksi, termasuk penyakit TBC yang disebabkan oleh bakteri Mycobacterium tuberculosis.

Surabaya sebagai kota terbesar kedua di Indonesia dengan luas wilayah kurang lebih $326,37 \mathrm{~km}^{2}$ dan dengan jumlah penduduk kurang lebih 2.801.409 jiwa, secara administratif terbagi dalam 31 kecamatan dimana 11 kecamatan yang ada di Kota Surabaya terletak diwilayah pesisir dengan jumlah penderita TBC terbesar di Sura-baya. Menurut Penelitian sebelumnya yang diru juk dalam (Prabawati, A.D., 2012) Wilayah pe-sisir identik dengan kemiskinan, yang disebab kan karena kurangnya akses kepada sumber-sumber modal, akses terhadap teknologi, akses terhadap pasar maupun rendahnya partisipasi masyarakat dalam pengelolaan sumber daya alam, partumbuhan jumlah penduduk yang tinggi, dan rendahnya tingkat pendidikan. Kecamatan kecamatan yang berada diwilayah pesisir Surabaya antara lain Kecamatan Benowo, Asem Rowo, Krembangan, Pabean Cantian, Semampir, Kenjeran, Bulak, Mulyorejo, Sukolilo, Rungkut dan Gunung Anyar. Penelitian tentang PHBS dari rumah tangga dengan penderita TBC di Indonesia beberapa kali telah dilakukan diantaranya adalah penelitian yang dila kukan (Kurniawan, D. A.,
2010) tentang hu-bungan PHBS dengan kejadian TBC paru pada warga di Kelurahan Jarakrasi, Wonosobo. Hasil penelitian menunjukkan bahwa terdapat hubungan antara PHBS dengan kejadian TBC pada warga di Kelurahan Jarakrasi, Wonosobo. Selain itu, (Puang, E. M., 2016) juga menga nalisis ten-tang pengaruh faktor-faktor lingkungan, pelayan an kesehatan dan perilaku hidup sehat terhadap keter jangkitan TBC di Surabaya. Diperoleh hasil bahwa adanya hubungan yang sangat kuat antara faktorfaktor lingkungan, pela yanan kesehatan dan perilaku hidup sehat terhadap keterjangkitan TBC di Surabaya.

Pada penelitian ini mengangkat tema rumah tangga penderita TBC berPHBS di wilayah pesisir Kota Surabaya. Diharap kan dapat diketahui faktor-faktor yang mempengaruhi perilaku hidup bersih dan sehat dari rumah tangga dengan penderita TBC dengan menggunakan regresi logis tik biner, karena ingin mencari hubungan antara variabel respon yang bersifat dichotomus (skala nominal atau ordinal dengan 2 kategori) terhadap variabel prediktor yang bersifat kategorik maupun kontinu. Berdasarkan hal tersebut maka perumusan masalah dalam penelitian ini adalah sebagai berikut

1. Bagaimana karakteristik PHBS
rumah tangga penderita TBC?

2. Apakah faktor-faktor yang mempengaruhi PHBS pada rumah tangga penderita TBC?

3. Berapakah peluang dari faktor yang mempengaruhi PHBS pada rumah tangga penderita TBC?

Berdasarkan permasalahan di atas, maka tujuan dari penelitian ini adalah sebagai berikut.

1. Mendeskripsikan karakteristik PHBS rumah tangga dengan penderita TBC. 


\section{Eksakta Vol. 18 No. 2 Oktober 2017}

E-ISSN : 2549-7464, P-ISSN : 1411-3724

2. Menentukan faktor-faktor yang mempengaruhi PHBS rumah tangga dengan penderita TBC.

3. Mengetahui seberapa besar peluang faktor-faktor yang mempengaruhi PHBS pada rumah tangga dengan pen derita TBC.

Hasil dari penelitian ini diharapkan dapat memberikan memberikan informasi kepada masyarakat mengenai faktorfaktor yang mempengaruhi PHBS rumah tangga penderita TBC di wilayah pesisir Kota Surabaya. Berdasarkan informasi tersebut diharapkan dapat menjadi wacana dalam program menggalakkan PHBS oleh Dinas Kesehatan Kota Surabaya

\section{Metode Penelitian}

\section{A. Sumber Data}

Data yang digunakan dalam peneli tian ini berupa data primer dan data sekun der. Data primer adalah data yang dipero leh secara langsung dengan melaku kan survey pada rumah tangga dengan pende rita TBC yang meliputi 39 variabel. Se dangkan data sekunder adalah data jumlah pasien penderita TBC dari puskes mas di masing-masing kecamatan yang terletak di wilayah pesisir Kota Surabaya.

\section{B. Metode Pengambilan Sampel}

Pengambilan sampel pada penelitian

menggunakan metode Simple Random Sampling /SRS (Scheaffer, Mendenhal III, Ott, \& Gerow, 2011) dengan taksiran parameter proporsional. Proporsi $(p)$ yang digunakan dalam perhitungan merupa kan perbandingan antara status PHBS baik dan status PHBS kurang dari rumah tangga dengan penderita TBC. Namun pada penelitian ini ditetapkan $p$ sebesar 0,5 dikarena tidak ada informasi dari penelitian terdahulu. Dengan mengguna kan batas kesalahan estimasi (B) sebesar 0,070 maka diperoleh jumlah sampel $(n)$ sebanyak 172 .

\section{Metode Analisis Data}

Untuk mengetahui faktor-faktor yang mempengaruhi PHBS rumah tangga dengan penderita TBC di pesisir Surabaya digunakan analisis regresi logistik biner. Regresi logistik biner adalah metode sta tistik yang digunakan untuk mencari hubungan antara variabel respon $(Y)$ yang memiliki skala data nominal (dua kategori atau biner) dengan variabel prediktor $(X)$ yang bersifat kategorik maupun kontinu. Setiap pengamatan pada objek diklasifi-kasikan sebagai "sukses" atau "gagal" yang dinotasikan 1 atau 0 . Untuk penga-matan ke- $i$ dari sampel $(i=1,2, \ldots, n)$, variabel $Y_{i}$ mengikuti distribusi Bernoulli dengan parameter $\pi_{i}$, memiliki fungsi probabilitas sebagai berikut (Hosmer, D. W. \& Lemeshow, S., 2013).

$$
f\left(y_{i}, \pi_{i}\right)=\pi^{y_{i}}\left(1-\pi_{i}\right)^{1-y_{i}} ; \mathrm{y}_{\mathrm{i}}=0,1 \text {; }
$$

Model regresi logistik dari y yang dinyatakan sebagai fungsi $x$ adalah seba gai berikut.

$\pi(x)=\frac{\exp \left(\beta_{0}+\beta_{1} x_{1}+\beta_{2} x_{2}+\ldots+\beta_{p} x_{p}\right)}{1+\exp \left(\beta_{0}+\beta_{1} x_{1}+\beta_{2} X_{2}+\ldots+\beta_{p} x_{p}\right)}$

\section{Variabel Penelitian}

Variabel-variabel yang diukur untuk mencapai tujuan peneliti meliputi variabel respon dan variabel prediktor. Variabel respon yang digunakan dalam penelitian ini adalah status PHBS dari Rumah Tangga dengan Penderita TBC yang berskala nominal dengan dua kaetgorik yaitu sebagai berikut.

$\mathrm{Y}=0$ : rumah tangga dengan PHBS baik (Akumulasi skor PHBS $\geq 7$ )

$\mathrm{Y}=1$ : rumah tangga dengan $\mathrm{PHBS}$ kurang (Akumulasi skor PHBS < 7) 


\section{Eksakta Vol. 18 No. 2 Oktober $\mid 2017$}

\section{E-ISSN : 2549-7464, P-ISSN : 1411-3724}

Penilaian PHBS dari rumah tangga dengan penderita TBC diukur sesuai dengan 10 indikator PHBS untuk rumah tangga dengan penderita TBC, sehingga nilai tertinggi adalah 10 . Rumah tangga dikategorikan 1 apabila memenuhi kriteria sebagai rumah tangga dengan PHBS baik, sedangkan rumah tangga dikategorikan 0 apabila memenuhi kriteria sebagai rumah tangga kurang berPHBS. Rumah tangga dikategorikan berPHBS baik adalah rumah tangga dengan total nilai indikator sebesar 7 atau lebih dengan syarat indi-kator PHBS yang tidak terpenuhi adalah indikator yang masih dapat ditoleransi, dan dikategorikan kurang ber-PHBS apa bila total nilai indikator kurang dari 7. Skor PHBS diukur dengan 10 pertanyaan indikator PHBS. Skor 1 untuk jawaban "ya" dan 0 untuk "tidak". Akumulasi skor PHBS tersebut dicocokan dengan klasifikasi PHBS sesuai pengkategorikan (Anonim_2, 2013).

Variabel Prediktor adalah variabel yang digunakan untuk mengetahui faktorfaktor yang mempengaruhi perilaku hidup bersih dan sehat dari rumah tangga dengan penderita TBC sebanyak 39 variabel.

Tabel 1. Variabel Prediktor

\begin{tabular}{|c|c|c|c|}
\hline \multicolumn{4}{|c|}{ Karakteristik Sosial Ekonomi Keluarga } \\
\hline Variabel & Keterangan & Kategori & Skala \\
\hline $\mathrm{X}_{1}$ & Usia Kepala Rumah Tangga & ..... Tahun & Rasio \\
\hline $\mathrm{X}_{2}$ & Usia Istri & ..... Tahun & Rasio \\
\hline $\mathrm{X}_{3}$ & $\begin{array}{l}\text { Pendidikan Terakhir } \\
\text { Kepala Rumah Tangga }\end{array}$ & $\begin{array}{l}1=\text { Tidak Sekolah } \\
2=\text { SD } / \text { MI/Sederajat } \\
3=\text { SMP } / \text { MTs } / \text { Sederajat } \\
4=\text { SMA/MA/Sederajat } \\
5=\text { PT/Sederajat }\end{array}$ & Ordinal \\
\hline $\mathrm{X}_{4}$ & $\begin{array}{c}\text { Pendidikan Terakhir } \\
\text { Isteri }\end{array}$ & $\begin{array}{l}1=\text { Tidak Sekolah } \\
2=\text { SD/MI/Sederajat } \\
3=\text { SMP } / \text { MTs/Sederajat } \\
4=\text { SMA/MA/Sederajat } \\
5=\text { PT/Sederajat }\end{array}$ & Ordinal \\
\hline $\mathrm{X}_{5}$ & $\begin{array}{c}\text { Pekerjaan Kepala Rumah } \\
\text { Tangga }\end{array}$ & $\begin{array}{l}1=\text { Pegawai Swasta } \\
2= \\
\text { Pedagang/Wiraswasta } \\
3=\text { Serabutan } \\
4=\text { Tidak } \\
\text { Bekerja/Pensiunan }\end{array}$ & Nominal \\
\hline $\mathrm{X}_{6}$ & Status Pekerjaan Isteri & $\begin{array}{l}1=\text { Tidak } \\
2=\text { Ya }\end{array}$ & Nominal \\
\hline $\mathrm{X}_{7}$ & $\begin{array}{c}\text { Jumlah Anggota } \\
\text { Keluarga }\end{array}$ & $\begin{array}{l}1=<7 \text { Orang } \\
2=\geq 7 \text { Orang }\end{array}$ & Nominal \\
\hline
\end{tabular}

Tabel 1. Lanjutan

\begin{tabular}{|c|c|c|c|}
\hline Variabel & Keterangan & Kategori & Skala \\
\hline $\mathrm{X}_{8}$ & $\begin{array}{c}\text { Punya Anak Usia } \\
\text { Sekolah }\end{array}$ & $\begin{array}{l}1=\text { Tidak } \\
2=\text { Ya }\end{array}$ & Nominal \\
\hline $\mathrm{X}_{9}$ & $\begin{array}{c}\text { Kepemilikan Anak } \\
\text { Usia Balita } \\
\end{array}$ & $\begin{array}{l}1=\text { Tidak } \\
2=\text { Ya }\end{array}$ & Nominal \\
\hline $\mathrm{X}_{10}$ & $\begin{array}{c}\text { Asal Daerah Rumah } \\
\text { Tangga }\end{array}$ & $\begin{array}{c}1=\text { Asli Surabaya } \\
2=\begin{array}{c}\text { Luar Surabaya } \\
\text { (Pendatang) }\end{array}\end{array}$ & Nominal \\
\hline $\mathrm{X}_{11}$ & Status Kependudukan & $\begin{array}{c}1=\text { Penduduk Surabaya } \\
\text { (KTP Tetap) } \\
2=\text { Bukan Penduduk } \\
\text { Surabaya(KTP Musiman) }\end{array}$ & Nominal \\
\hline $\mathrm{X}_{12}$ & $\begin{array}{l}\text { Pendapatan Rumah } \\
\text { Tangga }\end{array}$ & Rp. ...... & Rasio \\
\hline $\mathrm{X}_{13}$ & $\begin{array}{l}\text { Pengeluaran Rumah } \\
\text { Tangga }\end{array}$ & Rp. ...... & Rasio \\
\hline \multicolumn{4}{|c|}{ Sanitasi } \\
\hline \multicolumn{4}{|c|}{ a. Kondisi Fisik Rumah } \\
\hline $\mathrm{X}_{14}$ & Kepemilikan Rumah & $\begin{array}{l}1=\text { Milik Sendiri } \\
2=\text { Kontrak } \\
3=\text { Sewa } / \text { Kos } \\
4=\text { Lainnya }\end{array}$ & Nominal \\
\hline $\mathrm{X}_{15}$ & Jenis Atap Terluas & $\begin{array}{l}1=\text { Genteng } \\
2=\text { Asbes } / \text { Seng } \\
3=\text { Rumbia } \\
4=\text { Lainnya }\end{array}$ & Nominal \\
\hline $\mathrm{X}_{16}$ & Jenis Dinding Terluas & $\begin{array}{l}1=\text { Batu Bata } \\
2=\text { Kayu } \\
3=\text { Ijuk } / \text { Bambu }\end{array}$ & Nominal \\
\hline $\mathrm{X}_{17}$ & Jenis Lantai Terluas & $\begin{array}{l}1=\text { Keramik } / \text { Porselen } \\
2=\text { Plester } / \text { Semen } \\
3=\text { Tanah }\end{array}$ & Nominal \\
\hline $\mathrm{X}_{18}$ & Ventilasi Rumah & $\begin{array}{l}1=\text { Ada, Luasnya }<10 \% \\
\text { Luas Lantai } \\
2=\text { Ada, Luasnya } \geq 10 \% \\
\text { Luas Lantai } \\
\text { 3= Tidak Ada }\end{array}$ & Nominal \\
\hline $\mathrm{X}_{19}$ & $\begin{array}{l}\text { Kepadatan Hunian } \\
\text { Rumah }\end{array}$ & $\begin{array}{c}1=\text { Tidak Memenuhi } \\
\text { Syarat }<8 \mathrm{~m}^{2} / \text { Orang } \\
2=\text { Memenuhi Syarat } \geq \\
8 \mathrm{~m}^{2} / \text { Orang }\end{array}$ & Nominal \\
\hline \multicolumn{4}{|c|}{ b. Sarana Rumah Tangga } \\
\hline $\mathrm{X}_{20}$ & \begin{tabular}{|l|} 
Kepemilikan \\
Toilet/WC/Jamban
\end{tabular} & $\begin{array}{l}1=\text { Umum } \\
2=\text { Sendiri }\end{array}$ & Nominal \\
\hline $\mathrm{X}_{22}$ & $\begin{array}{l}\text { Tempat Pembuangan } \\
\text { Sampah }\end{array}$ & $\begin{array}{l}1=\text { Dalam Lubang } / \text { Dibakar } \\
2=\text { Tempat Sampah } \\
3=\text { Dibuang ke Sungai }\end{array}$ & Nominal \\
\hline $\mathrm{X}_{23}$ & $\begin{array}{l}\text { Tempat Pembuangan Air } \\
\text { Limbah }\end{array}$ & $\begin{array}{l}1 \text { = Langsung ke got } \\
\quad / \text { sungai/pantai } \\
2=\text { Lainnya }\end{array}$ & Nominal \\
\hline \multicolumn{4}{|c|}{ c. Sumber Air } \\
\hline $\mathrm{X}_{21}$ & Sumber Air Bersih & $\begin{array}{l}1=\text { PDAM } \\
2=\text { Sumur } \\
3 \text { = Lainnya }\end{array}$ & Nominal \\
\hline \multicolumn{4}{|c|}{ d. $\quad$ Sumber Listrik } \\
\hline $\mathrm{X}_{24}$ & Jenis Penerangan & $\begin{array}{l}1=\text { PLN Sendiri } \\
2=\text { PLN Menyalur }\end{array}$ & Nominal \\
\hline \multicolumn{4}{|c|}{ Karakteristik Penderita TBC dalam Rumah Tangga } \\
\hline $\mathrm{X}_{25}$ & Jumlah Penderita TBC & ..... Orang & Rasio \\
\hline $\mathrm{X}_{26}$ & $\begin{array}{l}\text { Kedudukan Penderita } \\
\text { TBC }\end{array}$ & $\begin{array}{l}1=\text { Suami } \\
2=\text { Isteri } \\
3=\text { Anak } \\
4=\text { Suami dan Isteri } \\
5=\text { Suami dan Anak } \\
6=\text { Isteri dan Anak } \\
7=\text { Suami, Isteri dan Anak } \\
8=\text { Keluarga }\end{array}$ & Nominal \\
\hline $\mathrm{X}_{27}$ & $\begin{array}{l}\text { Lama Menderita } \\
\text { Penyakit TBC }\end{array}$ & $\begin{array}{l}1=>6 \text { Bulan } \\
2=\leq 6 \text { Bulan }\end{array}$ & Nominal \\
\hline $\mathrm{X}_{28}$ & Status TBC & $\begin{array}{l}1=\text { TBC Paru BTA Negatif } \\
2=\text { TBC Paru BTA Positif }\end{array}$ & Nominal \\
\hline $\mathrm{X}_{29}$ & $\begin{array}{l}\text { Riwayat Penyakit yang } \\
\text { diderita Penderita }\end{array}$ & $\begin{array}{l}1=\text { Ada } \\
2=\text { Tidak Ada }\end{array}$ & Nominal \\
\hline
\end{tabular}




\section{Eksakta Vol. 18 No. 2 Oktober 2017}

E-ISSN : 2549-7464, P-ISSN : 1411-3724

\begin{tabular}{|l|l|l|l|}
\hline \multicolumn{4}{|c|}{ Perilaku Hidup Bersih dan Sehat } \\
\hline $\mathrm{X}_{30}$ & Menjemur alat tidur. & $\begin{array}{l}1=\text { Ya } \\
2=\text { Tidak }\end{array}$ & Nominal \\
\hline
\end{tabular}

Tabel 1. Lanjutan

\begin{tabular}{|c|c|c|c|}
\hline Variabel & Keterangan & Kategori & Skala \\
\hline $\mathrm{X}_{26}$ & $\begin{array}{l}\text { Kedudukan Penderita } \\
\text { TBC }\end{array}$ & $\begin{array}{l}1=\text { Suami } \\
2=\text { Isteri } \\
3=\text { Anak } \\
4=\text { Suami dan Isteri } \\
5=\text { Suami dan Anak } \\
6=\text { Isteri dan Anak } \\
7=\text { Suami, Isteri dan } \\
\text { Anak } \\
8=\text { Keluarga }\end{array}$ & Nominal \\
\hline $\mathrm{X}_{27}$ & $\begin{array}{l}\text { Lama Menderita } \\
\text { Penyakit TBC }\end{array}$ & $\begin{array}{l}1=>6 \text { Bulan } \\
2=\leq 6 \text { Bulan }\end{array}$ & Nominal \\
\hline $\mathrm{X}_{28}$ & Status TBC & 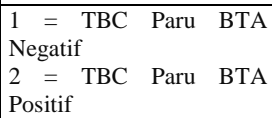 & Nominal \\
\hline $\mathrm{X}_{29}$ & $\begin{array}{l}\text { Riwayat Penyakit yang } \\
\text { diderita Penderita }\end{array}$ & $\begin{array}{l}1=\text { Ada } \\
2=\text { Tidak Ada }\end{array}$ & Nominal \\
\hline \multicolumn{4}{|c|}{ Perilaku Hidup Bersih dan Sehat } \\
\hline $\mathrm{X}_{30}$ & Menjemur alat tidur. & $\begin{array}{l}1=\text { Ya } \\
2=\text { Tidak }\end{array}$ & Nominal \\
\hline $\mathrm{X}_{31}$ & $\begin{array}{l}\text { Kebiasaan membuka } \\
\text { pintu dan jendela setiap } \\
\text { pagi agar udara dan sinar } \\
\text { matahari masuk. }\end{array}$ & $\begin{array}{l}1=\text { Ya } \\
2=\text { Tidak }\end{array}$ & Nominal \\
\hline $\mathrm{X}_{32}$ & $\begin{array}{l}\text { Kebiasaan Merokok dan } \\
\text { Konsumsi Alkohol }\end{array}$ & $\begin{array}{l}1=\text { Merokok Tidak } \\
\text { Minum Alkohol } \\
2=\text { Minum Alkohol Tidak } \\
\text { Merokok } \\
3 \text { = Merokok dan Minum } \\
\text { Alkohol } \\
4=\text { Tidak Keduanya }\end{array}$ & Nominal \\
\hline $\mathrm{X}_{33}$ & Olahraga secara teratur & $\begin{array}{l}1=\text { Ya } \\
2=\text { Tidak }\end{array}$ & Nominal \\
\hline $\mathrm{X}_{34}$ & $\begin{array}{c}\text { Makan Makanan } \\
\text { Bergizi }\end{array}$ & $\begin{array}{l}1=\text { Ya } \\
2=\text { Tidak }\end{array}$ & Nominal \\
\hline $\mathrm{X}_{35}$ & $\begin{array}{c}\text { Kebiasaan Mencuci } \\
\text { Pakaian dengan Air } \\
\text { Bersih dan Sabun } \\
\text { dengan bersih }\end{array}$ & $\begin{array}{l}1=\text { Ya } \\
2=\text { Tidak }\end{array}$ & Nominal \\
\hline $\mathrm{X}_{36}$ & $\begin{array}{c}\text { Menggunakan Jamban } \\
\text { Sehat }\end{array}$ & $\begin{array}{l}1=\text { Ya } \\
2=\text { Tidak }\end{array}$ & Nominal \\
\hline $\mathrm{X}_{37}$ & $\begin{array}{c}\text { Mencuci Tangan } \\
\text { dengan Air Bersih dan } \\
\text { Sabun }\end{array}$ & $\begin{array}{l}1=\text { Ya } \\
2=\text { Tidak }\end{array}$ & Nominal \\
\hline $\mathrm{X}_{38}$ & Siklus Itirahat Cukup & $\begin{array}{l}1=\text { Ya } \\
2=\text { Tidak }\end{array}$ & Nominal \\
\hline $\mathrm{X}_{39}$ & $\begin{array}{l}\text { Pemisahan Peralatan } \\
\text { Makan \&Tidur }\end{array}$ & $\begin{array}{l}1=\text { Ya } \\
2=\text { Tidak }\end{array}$ & Nominal \\
\hline
\end{tabular}

\section{Hasil dan Pembahasan}

Pada analisis dan pembahasan akan dijelaskan mengenai karakteristik penderita TBC di wilayah Pesisir Surabaya kemudian dilanjutkan dengan melakukan pemodelan analisis PHBS pada rumah tangga dengan penderita TBC. Metode statistik yang digunakan meliputi analisis deskriptif dan regresi logistik biner.

\section{A. Perkembangan Status PHBS Tahun 2014-2015}

Karakteristik status PHBS rumah tangga di wilayah Pesisir Surabaya tahun 2014 ditampilkan pada Gambar 1.

Gambar 1 tahun 2014 dapat diketahui bahwa dari 11 kecamatan di wilayah pesi-

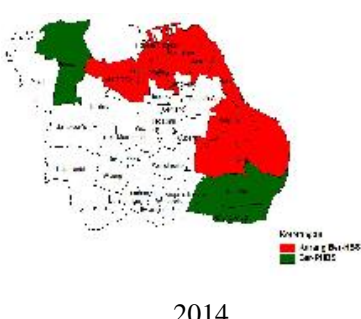

2014

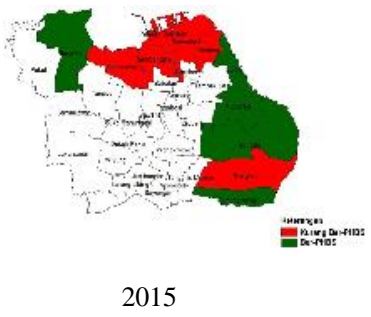

Gambar 1. Persentase Rumah Tangga Ber-PHBS Menurut Tahun

sir Surabaya terdapat tiga kecamatan yang memiliki persentase jumlah rumah tangga berperilaku hidup bersih dan sehat (ber-PHBS) yang tinggi yaitu Kecamatan Benowo, Gunung Anyar dan Rungkut yaitu dengan persentase sebesar $70 \%$ atau lebih. Sedangkan wilayah pesisir lainnya merupakan wilayah kurang ber-PHBS. Gambar 1 tahun 2015 menunjukkan dari 11 kecamatan di wilayah pesisir Surabaya terdapat lima kecamatan yang memiliki persentase jumlah rumah tangga berperilaku hidup bersih dan sehat (berPHBS) yang tinggi yaitu Kecamatan Benowo, Bulak, Mulyorejo, Sukolilo dan Gunung Anyar yaitu dengan persentase sebesar $70 \%$ atau lebih. Sedangkan wilayah pesisir lainnya merupakan wilayah kuarng ber-PHBS Dari Gambar 1 dapat diketahui perkembangan status PHBS di wilayah pesisir Surabaya berdasarkan tahun 2014 dan 2015, tampak pada tahun 2015 ada kenaikan jumlah kecamatan dengan persentase jumlah rumah tangga yang ber-PHBS tinggi, namun kecamatan Rungkut mengalami penurunan dalam jumlah rumah tangga yang ber-PHBS sehingga masuk kedalam kelompok kecamatan 


\section{Eksakta Vol. 18 No. 2 Oktober $\mid 2017$}

dengan jumlah rumah tangga ber-PHBS kurang dari $70 \%$.

\section{B. Kondisi PHBS dalam Rumah Tangga}

Analisis statistika deskriptif digunakan untuk mengetahui karakteristik responden berdasarkan perilaku hidup bersih dan sehat.

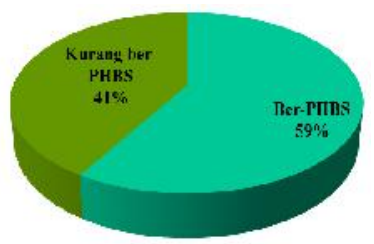

Gambar 2. Status PHBS Rumah Tangga

Gambar 2 menunjukkan bahwa 59\% rumah tangga memiliki status ber-PHBS sedangkan sisanya sisanya $41 \%$ rumah tangga memiliki status kurang ber-PHBS.
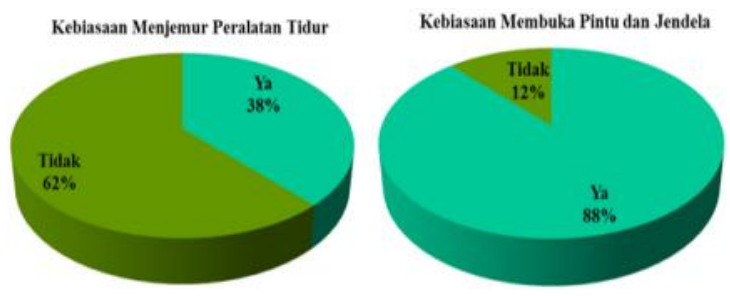

Gambar 3. Kebiasaan Rumah Tangga

Gambar 3 menunjukkan bahwa hanya $38 \%$ rumah tangga yang memiliki kebiasaan menjemur peralatan tidur dan $88 \%$ rumah tangga memiliki kebiasaan membuka pintu dan jendela rumah atau ventilasi setiap pagi hari.

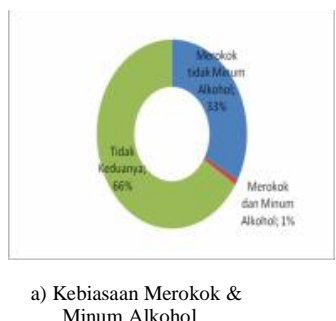

Minum Alkohol

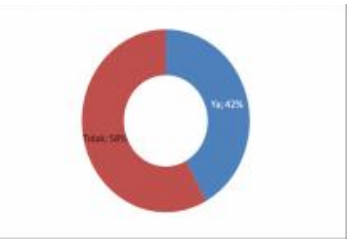

Gambar 4. Kebiasaan Anggota Rumah Tangga

Gambar 4 menunjukkan bahwa $66 \%$ anggota rumah tangga tidak memiliki kebiasaan merokok dan minum alkohol/

\section{E-ISSN : 2549-7464, P-ISSN : 1411-3724}

minuman keras sedangkan 33\% anggota rumah tangga memiliki kebiasaan mero kok tetapi tidak minum alkohol dan anggo ta rumah tangga memiliki kebiasaan mero kok dan minum alkohol hanya $1 \%$. Dalam hal kebiasaan berolah raga, 58\% anggota rumah tangga tidak biasa berolahraga.

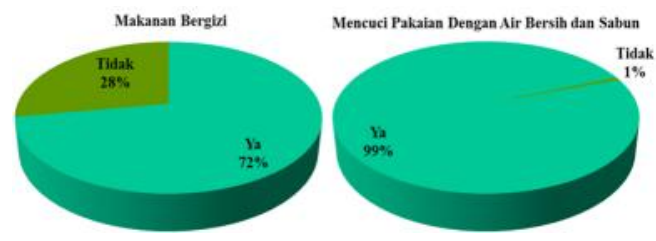

Gambar 5. Kebiasaan Makan Makanan Bergizi dan Mencuci Pakaian Dengan Bersih

Gambar 5 menunjukkan bahwa $72 \%$ rumah tangga memiliki pola makanan bergizi sedangkan $28 \%$ rumah tangga lainnya tidak, dan $99 \%$ rumah memiliki kebiasaan mencuci pakaian menggunakan air bersih dan deterjen.

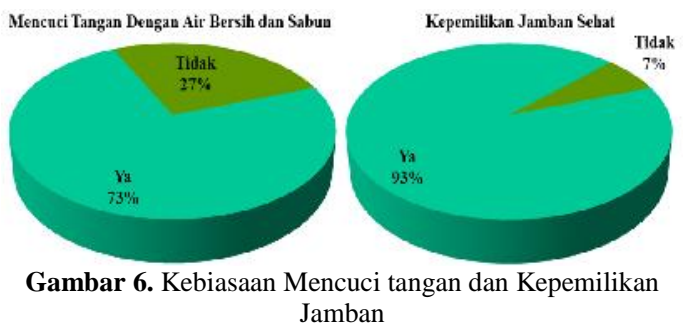

Gambar 6 menunjukkan bahwa $73 \%$ rumah tangga memiliki kebiasaan mencu-ci tangan menggunakan air bersih dan sabun, dan 93\% rumah tangga memiliki jamban sehat dirumah dan $7 \%$ sisanya rumah tangga tidak memiliki jamban sehat dirumah.

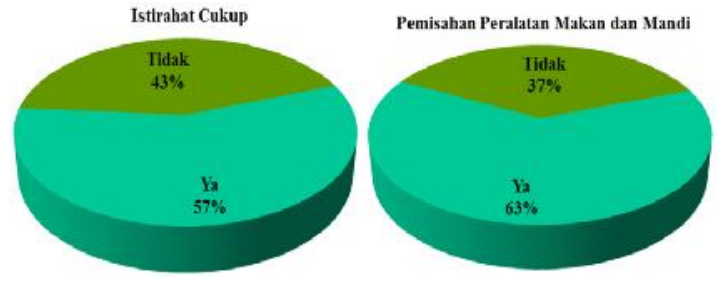

Gambar 7. Anggota Rumah Tangga Memiliki Kebiasaan Istirahat Cukup Dan Memisahkan Alat Makan \& Mandi 
E-ISSN : 2549-7464, P-ISSN : 1411-3724

Gambar 7 juga menunjukkan bahwa $63 \%$ rumah tangga memiliki kebiasaan memisah peralatan makan dan mandi antar anggota keluarga dan sisanya $37 \%$ rumah tangga tidak memiliki kebiasaan memisah peralatan makan dan mandi antar anggota keluarga. Gambar 7 juga menunjukkan bahwa 57\% rumah tangga memiliki siklus istirahatyang cukup.

\section{Faktor-Faktor Yang Mempengaruhi PHBS Rumah Tangga Penderita $T B C$}

Untuk mengetahui faktor-faktor yang mempe-ngaruhi PHBS rumah tangga dengan penderita TBC di pesisir Surabaya digunakan analisis regresi logistik biner. Kemudian dilakukan pengujian seca ra serentak dan parsial untuk mengetahui variabel yang signifikan. Variabel respon yang digunakan adalah status rumah tangga ber-PHBS (Y) yang terdiri dari dua kategori, yaitu rumah tangga kurang berPHBS dan rumah tangga ber-PHBS. Model logit yang terbentuk adalah seperti berikut ini

$$
\begin{aligned}
g(X)= & 19,526-4,027 X_{31(1)}+3,414 X_{32(1)}-6,170 X_{33(1)}-5,788 X_{34(1)}+ \\
& -5,621 X_{37(1)}-5,209 X_{38(1)}-7,016 X_{39(1)}
\end{aligned}
$$

Berdasarkan model logit tersebut disusunlah bentuk model regresi logistik biner sebagai berikut

$$
\pi(x)=\frac{\exp \left(\begin{array}{l}
19,526-4,027 X_{31(1)}+3,414 X_{32(1)}-6,170 X_{33(1)}-5,788 X_{34}(1) \\
-5,621 X_{37}(1)-5,209 X_{38}(1)-7,016 X_{39}(1)
\end{array}\right)}{1+\exp \left(\begin{array}{l}
19,526-4,027 X_{31}(1)+3,414 X_{32}(1)-6,170 X_{33}(1)-5,788 X_{34}(1) \\
-5,621 X_{37}(1)-5,209 X_{38}(1)-7,016 X_{39}(1)
\end{array}\right)}
$$

Berdasarkan model terbaik yang didapatkan dengan analisis regresi logistik biner metode Backward yang sesuai pada hasil uji signifikansi parameter dengan hanya menggunakan tujuh variabel pre diktor yang signifikan, maka dilakukan perhitungan nilai peluang untuk 2 kategori variabel respon. Nilai peluang faktor-faktor yang berpengaruh signifikan terha-dap rumah tangga dengan penderita TBC ber-PHBS dijelaskan sebagai berikut. Peluang Rumah Tangga dengan Penderita TBC di pesisir Surabaya yang memiliki kebiasaan membuka pintu dan jendela, tidak memiliki kebiasaan merokok dan minum alkohol, memiliki kebiasaan olahraga, memiliki pola makanan bergizi, memiliki kebiasaan cuci tangan dengan sabun dan air, memiliki siklus istirahat yang cukup serta melakukan pemisahan alat makan dan mandi akan tergolong Kurang berPHBS sebesar 0,00002 dan akan tergolong sebagai rumah tangga berPHBS sebesar 0,99998. Artinya apabila terdapat 100 rumah tangga dengan kondisi seperti tersebut di atas, maka 99 diantara nya akan merupakan rumah tangga ber-PHBS, sedangkan sisanya tergolong kurang ber-PHBS.

\section{Kesimpulan dan Saran}

\section{A. Kesimpulan}

Faktor-faktor yang mempengaruhi PHBS rumah tangga dengan penderita TBC di wilayah pesisir Surabaya adalah faktor kebiasaan membuka pintu dan jen dela, kebiasaan merokok dan minum alko hol, kebiasaan olahraga, makanan bergizi, kebiasaaan cuci tangan dengan sabun dan air bersih, istirahat cukup, pemisahan per alatan mandi dan makan pada tingkat signifikansi 5\%. Peluang rumah tangga dengan penderita TBC di pesisir Surabaya yang memiliki kebiasaan membuka pintu dan jendela, tidak memiliki kebiasaan me-rokok dan minum alkohol, memiliki ke-biasaan olahraga, memiliki pola makan an bergizi, memiliki kebiasaan cuci tangan dengan sabun dan air, memiliki siklus isti rahat yang cukup serta melakukan pemi sahan alat makan dan mandi akan tergo long sebagai rumah tangga kurang ber-PHBS sebesar 0,00002 dan akan tergolong rumah tangga yang ber-PHBS sebesar 0,99998. Artinya 


\section{Eksakta Vol. 18 No. 2 Oktober 2017}

E-ISSN : 2549-7464, P-ISSN : 1411-3724

apabila terdapat 100 rumah tangga dengan kondisi seperti di atas, maka 99 diantaranya merupakan rumah tangga yang ber-PHBS.

\section{B. Saran}

Berdasarkan kesimpulan dapat diketa hui bahwa faktor kebiasaan menjemur peralatan tidur, kebiasaan membuka pintu dan jendela, makanan bergizi, kepemilik an jamban sehat, kebiasaaan cuci tangan dengan sabun dan air bersih, dan istirahat cukup berpengaruh terhadap terciptanya rumah tangga dengan penderita TBC berperilaku hidup bersih dan sehat. Oleh karena itu, diperlukan penyuluhan dan sosialisasi secara berkala oleh Dinas Kese hatan dan lembaga-lembaga kesehatan lainnya khusunya untuk faktor-faktor yang mempengaruhi PHBS rumah tangga yakni sosialisai agar rumah tangga memiliki ke biasaan membuka pintu dan jendela, olah raga, cuci tangan dengan sabun dan air bersih serta melakukan pemisahan peralat an mandi dan makan antar anggota ke luarga. Selain itu juga larangan untuk ke biasaan merokok dan minum alkohol dan berpola makanan bergizi serta istirahat yang cukup agar rumah tangga dengan penderita $\mathrm{TBC}$ lebih berperan aktif dalam menjaga kebersihan dan kebiasaaan dalam menjaga kesehatan agar semua rumah tangga penderita TBC diwilayah pesisir menjadi rumah tangga ber-PHBS serta me nurunkan angka penularan dan penderita penyakit TBC.

\section{Daftar Pustaka}

Anonim_1, 2008. Buku Saku Rumah Tangga Ber-Perilaku Hidup Bersih dan Sehat. Jakarta: Pusat Promosi Kesehatan Departemen Kesehatan RI.

Anonim_2, 2013. Riset Kesehatan Dasar.

Jakarta: Badan Penelitian Dan
Pengembangan Kesehatan Kemente rian Kesehatan RI

Hosmer, D. W. \& Lemeshow, S., 2013. Applied Logitic Regression Third Edition, New York: John Wiley \& Sons.

Kurniawan, D. A., 2010, Hubungan Peri laku Hidup Bersih Dan Sehat (PHBS) Dengan Kejadian Tuberkulosis Paru Pada Warga di Kelurahan Jaraksari, Wonosobo Jawa Tengah. Yogya karta: Sekolah Tinggi Ilmu Kesehatan 'Aisyiyah

Prabawati, A. D., 2012. Faktor-Faktor Yang Memepengaruhi Rumah Tangga Nelayan Berperilaku Hidup Bersih dan Sehat Dengan Analisis Regresi Logsitik, Surabaya: ITS.

Puang, E. M., 2016. Pengaruh FaktorFaktor Lingkungan, Pelayanan Kesehatan Dan Perilaku Hidup Sehat Terhadap Keterjangkitan Tuberkulosis di Surabaya. Surabaya: Universitas Negeri Surabaya.

Wulandari, S. P., Susilaningrum, D., \& Latra, I. N. 2015. Analisis Ketahanan Pangan Rumah Tangga Terhadap Kasus Penderita Penyakit Tubercu losis dengan Pendekatan Geographi cally Weighted Poisson Regression (Studi Kasus Pantai Pesisir Surabaya" Surabaya: Lembaga Penelitian dan Pengabdian Kepada Masyarakat Insti tut Teknologi Sepuluh Nopember.

Scheaffer, R. L., Mendenhal III, W., Ott, R. L., \& Gerow, K. (2011). Elementary Survey Sampling 7th ed. Boston: Brooks/Cole. 